\title{
CURSO DE FÉRIAS EM NEUROCIÊNCIAS: DIVULGANDO A CIÊNCIA PARA ALUNOS DO ENSINO MÉDIO E PRÉ-VESTIBULAR EM NOVA FRIBURGO, RJ
}

\author{
Andressa Magalhães-Silva ${ }^{1}$, Maria Luiza Mendonça de Lima ${ }^{1}$, Thaís Barbosa Ferreira \\ Sant'Anna ${ }^{1}$, Pablo Batista Couto ${ }^{2}$, Marlos Passos Dias ${ }^{2}$, Caroline Fernandes-Santos ${ }^{3 *}$
}

${ }^{1}$ Acadêmica em Biomedicina, Universidade Federal Fluminense, Instituto de Saúde de Nova Friburgo, Nova Friburgo, RJ, Brazil. ${ }^{2}$ Bacharel em Fonoaudiologia, Universidade Federal Fluminense, Instituto de Saúde de Nova Friburgo. Nova Friburgo, RJ, Brasil. ${ }^{3} \mathrm{PhD}$ em Biologia Humana e Experimental, http://conscienciaciencia.wix.com/punf. Bióloga, Profa. Associada I de Neurociências e Neurobiologia, Universidade Federal Fluminense, Instituto de Saúde de Nova Friburgo. Nova Friburgo, RJ, Brasil.

Resumo: O conhecimento da neurociência se faz necessário a atuação de diversos profissionais da saúde. Sendo assim, optou-se por oferecer um curso de férias sobre a temática a alunos do ensino médio e pré-vestibular, para auxiliá-los na escolha da carreira profissional e para que conhecessem o ambiente universitário. O objetivo deste relato é discutir o planejamento e as estratégias utilizadas para a divulgação cientifica da neurociência, como parte do projeto de extensão consCIÊNCIA na CIÊNCIA. O curso foi planejado e executado pela professora de neurociências e graduandos em biomedicina e fonoaudiologia. Os temas função e organização do sistema nervoso, percepção sensorial, drogas e neurotransmissores, emoções e neurônios espelho foram abordados. Os recursos educacionais utilizados foram slides convencionais, slides interativos, vídeos, dinâmicas em grupo e atividades práticas. Vinte alunos participaram das atividades, subdivididos em duas turmas, com duração de dois dias. Eles se mostraram engajados com as atividades propostas e avaliaram o curso, professores e monitores como muito bom. A única crítica emitida foi o tempo de curso, que poderia ser maior. Os monitores da equipe avaliaram a sua participação como importante a formação acadêmica e para a consolidação de conhecimentos adquiridos na graduação. Ainda, alguns manifestaram o interesse pela docência e em continuar divulgando a ciência. Por fim, conclui-se que a divulgação científica deve ser feita de forma lúdica, interativa e dialógica, abordando o cotidiano. Ela é uma via de mão dupla, beneficiando tanto aqueles que a planejam quanto os que dela participam.

Palavras-chave: carreira, vestibular, aprendizagem significativa, trabalho em pequenos grupo, mentimeter, sistema nervoso.

*Autora para correspondência: Caroline Fernandes-Santos, R. Dr. Silvio Henrique Braune, 22, Centro, Nova Friburgo, RJ, 28.625.650. Telefone: +55 22 2528-7168. 


\begin{abstract}
Neuroscience knowledge is essential to several health professionals. Thus, it was offered a vacation course in neuroscience to high school and pre-college students to help them choose their professional careers as well as to be in the university environment. This report aims to discuss course planning and the strategies used to neuroscience communication, as part of the extension project consCIÊECIA na CIÊECIA. The course was planned and executed by the neuroscience professor and undergraduate students of biomedicine and speech and language therapy. Topics chosen were the function and organization of the nervous system, sensory perception, drugs and neurotransmitters, emotions, and mirror neurons. The educational resources were conventional and interactive slides (mentimeter), videos, group dynamics, and practice activities. Twenty students attended the course, and they were allocated into two classes, that last two days. They were engaged with the proposed activities and evaluated the course, teacher, and monitors as very good. The only critique was the course duration, which could last longer. The undergraduate students evaluated their participation as relevant to their academic education and to consolidate the knowledge acquired during their under graduation course. Yet, some of them expressed their interest in teaching and in acting in science communication. Finally, we concluded that science communication must be ludic, interactive, and dialogic, approaching everyday facts. It is a two-way avenue since it benefits the one planning the activities and the ones who participate as well.
\end{abstract}

Keywords: career, college admission, meaningful learning, work in small groups, mentimeter, nervous system.

\title{
Introdução
}

A precarização dos recursos nos Ensinos Fundamental e Médio aumenta a distância entre a comunidade científica e a população. Isso se deve a não priorização de investimentos na educação e a ausência de docentes qualificados em todas as áreas, não atendendo à necessidade de tornar o conhecimento científico cativante e acessível aos alunos. Essa cruel realidade reflete a incapacidade de oferecer uma formação crítica, resultando na dificuldade dos alunos em enfrentar problemas diários, seguir no ensino superior e transformar a própria realidade (Ivanissevich, 2009). Nesse cenário, a educação científica se torna uma vítima. Na escola, ao considerar o ensino da biologia humana, ou seja, da anatomia, fisiologia e neurociências, constata-se que ela é prejudicada pela escassez de recursos pedagógicos. Em geral, o livro didático é o principal ou único material utilizado, o que limita a compreensão do conteúdo (Cerri et al., 2015).

É importante divulgar a ciência aos jovens, contextualizando o conhecimento aprendido com a sua realidade e o seu dia a dia, a fim de tornar o assunto mais interessante e menos denso em sua compreensão. Assim, os alunos podem então quebrar as barreiras impostas pelo método educativo tradicional e ter mais autonomia na escolha da carreira profissional e ingresso no ensino superior. Neste sentido, existem diversas iniciativas de 
divulgação cientifica aos jovens, onde a escola vai à universidade por meio de visitas (Silva et al., 2016a) ou cursos de férias (Silva et al, 2016b), assim como a universidade vai à escola (Silva et al., 2018; Bertollo et al., 2018).

A atuação de muitos profissionais como, médicos, fonoaudiólogos, psicólogos, enfermeiros e pedagogos, depende da compreensão de aspectos cognitivos, emocionais, sociais e patológicos do ser humano (Takase, 2003). A saúde física e mental advém do Sistema Nervoso ( $\mathrm{SN}$ ), comandado pelo cérebro, e os avanços científicos e tecnológicos como a tomografia computadorizada e os estudos genéticos —, têm promovido uma maior compreensão dessa dinâmica de funcionamento. A neurociência, por seu caráter interdisciplinar que une estudos anatômicos e funcionais do cérebro e a fisiologia de todo o organismo, é um tema complexo e desafiador tanto para o docente ensinar, quanto para o discente aprender.

Diante do exposto, o objetivo deste relato é discutir o planejamento e as estratégias utilizadas para a divulgação cientifica da neurociência aos jovens. O curso faz parte do projeto de extensão universitária consCIÊNCIA na CIÊNCIA, realizado em um campus do interior da Universidade Federal Fluminense (UFF), no município de Nova Friburgo, região serrana do estado do Rio de Janeiro.

\section{Procedimentos metodológicos}

Seleção dos alunos

A divulgação dos cursos foi feita no site institucional da UFF, em portais online de notícias (p. ex., G1, A Voz da Serra e Nova Friburgo em Foco) e em reportagem exibida por emissora local de TV (Zoom TV Jornal). O público alvo foi alunos do $2^{\circ}$ e $3^{\circ}$ anos do Ensino Médio e curso pré-vestibular. A inscrição foi feita em formulário online (jotform.com) e, entre as informações solicitadas, estavam o nome da escola, rede de ensino (pública ou privada), curso de preferência e segunda e terceira opções de curso (caso não houvesse vaga em seu curso de preferência) e uma breve justificativa da escolha do curso. Também foi solicitado o envio de uma cópia do documento de identidade e comprovante de matrícula, para confirmar sua condição de estudante. 
A seleção dos alunos para o curso Neurociências Descomplicada foi feita através da justificativa pela escolha do curso. Foram ofertadas 32 vagas (16 por turma) e respeitou-se uma proporção de $70 \%$ de vagas para alunos de escola pública e 30\% para alunos de escolas privadas. Adiante seguem dois textos redigidos por candidatos selecionados:

“[...]me aproximar mais da matéria que eu amo e que desejo conhecer para agregar meus conhecimentos na área de psicologia [...]”"

"[...]oportunidade de ampliar conhecimento e direcionar minha escolha profissional que é a medicina especializada em neurologia, além de ter a oportunidade de conhecer uma instituição que tem grande importância na região."

\section{Escolha dos temas}

O curso foi planejado pela professora da disciplina de neurociências e alunos de graduação em biomedicina e fonoaudiologia. A partir de discussões realizadas em uma sala de aula virtual (edmodo.com) e reuniões presenciais, definiu-se temas e planos de aula, além da preparação de materiais. Inicialmente, os monitores fizeram um brainstorming de ideias, sugerindo temas como efeito das drogas no SN, visão, memória, aprendizado, percepção da dor e emoções, além de sugestões sobre possíveis atividades práticas e em grupo. Os monitores enfatizaram a importância de oferecer atividades interativas e lúdicas, que abordassem assuntos próximos à realidade e ao dia a dia dos alunos. A partir desses critérios, os temas foram selecionados. Como resultado, optou-se por abordar a função e organização do SN, percepção sensorial, drogas e neurotransmissores, emoções e neurônios espelho.

\section{Planejamento das atividades}

A equipe decidiu separar os temas escolhidos em dois dias (23 e 24 de julho de 2018), com carga horária de $6 \mathrm{~h}$ por turma, sendo uma turma no turno da manhã e outra à tarde. Os recursos educacionais escolhidos foram slides convencionais (power point), slides interativos (mentimeter.com), vídeos (youtube.com), dinâmicas em grupo e atividades práticas. Os monitores prepararam um plano de aula detalhando cada atividade, os recursos educacionais e materiais necessários, o qual foi revisado pela docente. Os dois meses que antecederam o curso foram utilizados para a obtenção e criação de materiais. 


\section{Dia 1}

No primeiro dia, foi proposto que os alunos respondessem em uma palavra o que a neurociências representa para eles através de slides interativos no aplicativo mentimeter. Em sequência, uma aula expositiva dialogada sobre o $S N$ e suas funções foi iniciada, através de slides convencionais. Dando seguimento, a primeira atividade prática foi proposta em grupos de três a quatro alunos, onde cada grupo recebeu um material impresso contendo um brain hat (“chapéu de cérebro", tradução livre dos autores) (Mchenry, 2000). O grupo deveria escrever o nome de cada lobo, colorir, recortar e montar um chapéu (Figura 1).

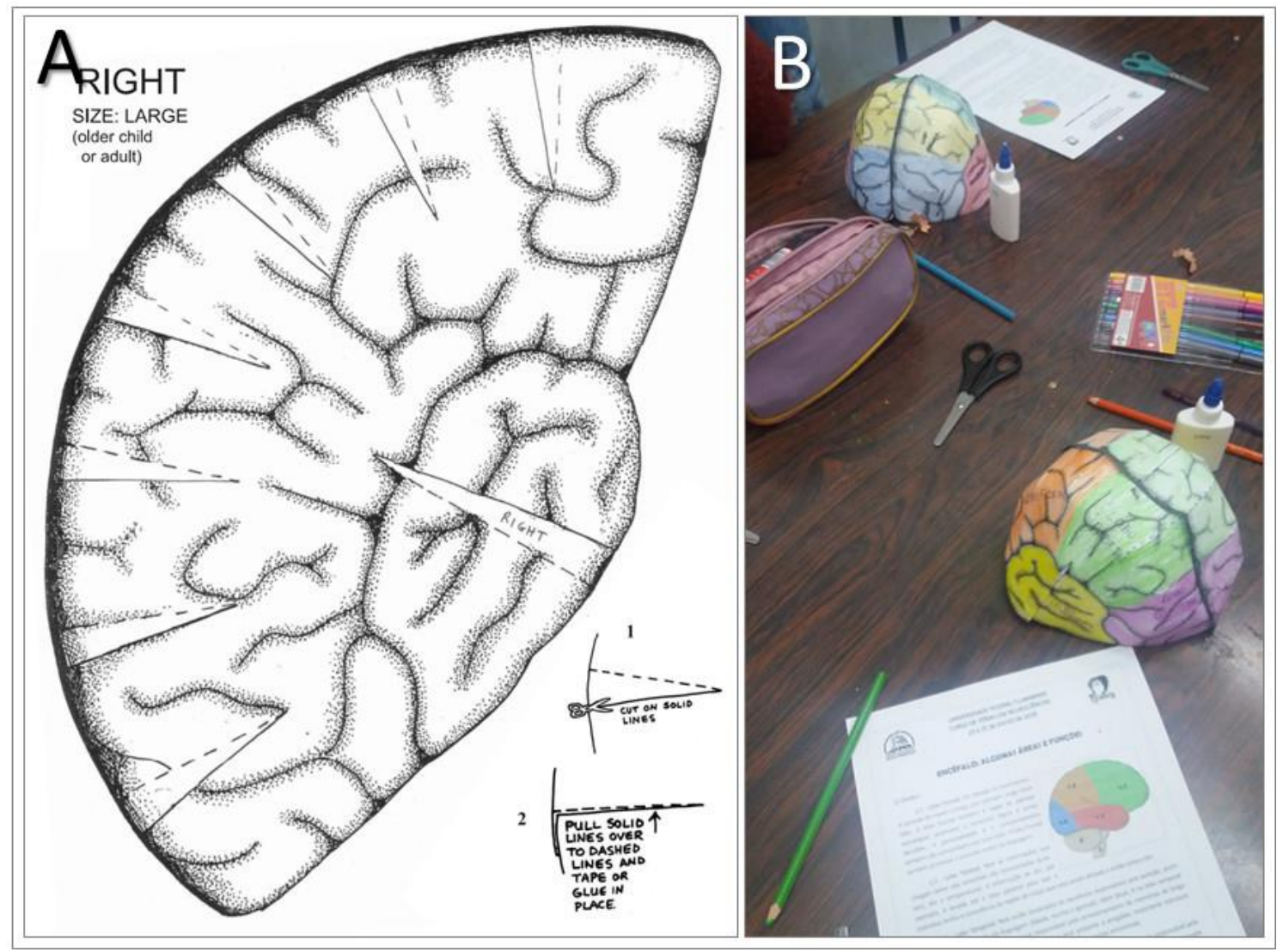

Figura 1 - Lobos do cérebro e suas funções. A, modelo do cérebro (brain hat) fornecido aos alunos. B, cérebros produzidos pelos alunos. Fonte: autores.

Em seguida, cada grupo recebeu um material impresso contendo um resumo sobre as funções dos lobos cerebrais, que deveria ser estudado e então devolvido para que não fosse mais consultado. Um dos monitores fez afirmações sobre a função dos lobos cerebrais e cada 
grupo deveria responder por escrito qual lobo as realiza. Ao final da atividade, foi identificado qual grupo acertou mais questões.

O próximo tema abordado foi drogas e cérebro, apresentado em slides convencionais e pela demonstração de vídeos. Foi explicado como as drogas alteram o funcionamento do SN e as consequências do seu uso abusivo. A última atividade do dia foi realizada através da demonstração da animação Mouse Party (Learn.Genetics). Nesta, são ilustrados e descritos os efeitos de sete drogas psicotrópicas sobre o funcionamento do cérebro de ratos.

\section{Dia 2}

O segundo dia iniciou-se com o tema emoções. Foram apresentados os conceitos, definições, funções e importância das emoções através de slides convencionais contendo vídeos e exemplos com o objetivo de introduzir e desenvolver o assunto. Durante a apresentação, foi feita uma enquete no mentimeter sobre emoções. Em seguida, expressões faciais foram demonstradas, caracterizadas e comparadas aos emojis frequentemente utilizados para comunicação em redes sociais e aplicativos de mensagens.

Em um segundo momento, uma dinâmica em grupo foi proposta para abordar o tema neurônios espelho e emoções. Enquanto um grupo executava a atividade, os demais deveriam permanecer externos a sala. Um aluno do grupo, intitulado "espectador (aluno 1)", assistiu a quatro vídeos curtos cujo conteúdo evocava diferentes emoções e, como consequência, alterava suas expressões faciais (Figura 2A-E). Dois alunos do mesmo grupo foram divididos em "observador primário (aluno 2)" e "observador secundário (aluno 3)". Ambos receberam uma folha contendo emojis que ilustrariam a emoção do espectador (Figura 2F-G).

O observador primário, disposto de modo que não era possível ver o vídeo (Figura 2E), observou a face do espectador e marcou na folha recebida o emoji que melhor representava a sua emoção. Por sua vez, o observador secundário, também sem ver o vídeo, analisou a face do observador primário e identificou o emoji que melhor descreveria a sua emoção. Nos grupos onde havia quatro participantes, o $4^{\circ}$ aluno ficou responsável por filmar a face do espectador.

Com o consentimento verbal dos alunos filmados, as filmagens foram exibidas posteriormente à turma para que todos pudessem observar as mudanças nas expressões faciais, agora cientes do conteúdo assistido. Ao final da dinâmica, os monitores compararam 
as opções marcadas pelos observadores primário e secundário e retomaram os conceitos expostos previamente sobre neurônios espelho e emoções.

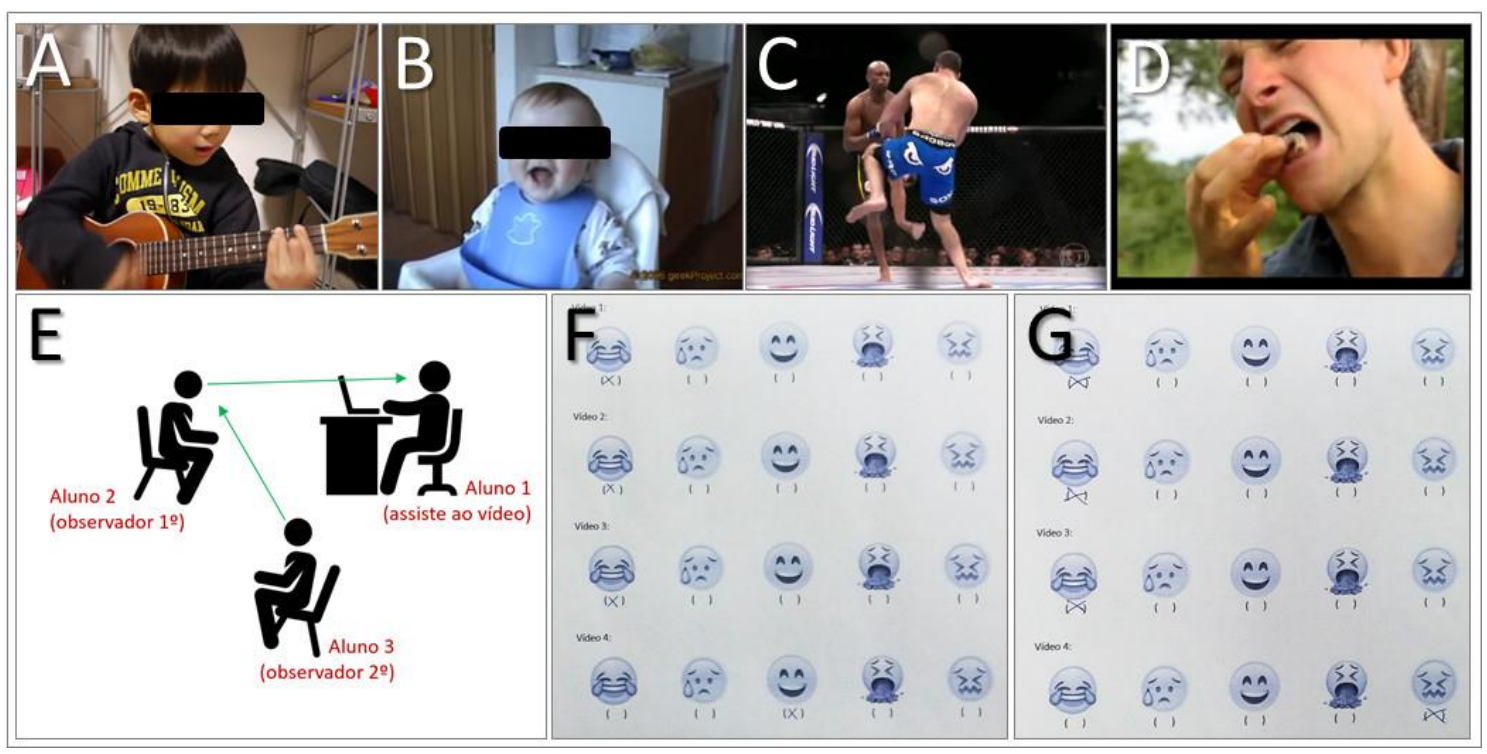

Figura 2 - Emoção e neurônios espelhos. A-B, vídeos selecionados para exibição. A, neste vídeo o menino toca violão e canta fazendo caretas. B, vídeo de um bebê gargalhando. C, trecho da luta onde o Anderson Silva fratura sua perna esquerda. D, homem comendo uma larva. E, disposição dos alunos na sala de aula, onde o aluno 1 assiste o vídeo portando fones de ouvido, o aluno 2 observa a face do aluno 1 e o aluno 3 observa a face do aluno 2. F-G, nesta folha, os alunos 2 e 3 indicavam os emojis que representariam a face do aluno observado. Fonte: autores.

Por último, foi realizada uma atividade para discutir a acurácia tátil do corpo. Os alunos foram novamente divididos em grupos e receberam um material de apoio, que consistia em um roteiro impresso contendo um mapa do corpo e um conjunto de palitos com três distancias diferentes (Figura 3A). Em cada grupo, um aluno foi vendado e outro ficou responsável por encostar os palitos em diferentes regiões do seu corpo (Figura 3B). O aluno vendado deveria relatar se sentia o toque de um ou dois pontos em sua pele, enquanto os demais alunos registrariam os achados no roteiro (Figura 3C). Ao final, um mapa da acurácia tátil do corpo deveria ser preenchido, conforme ilustrado na Figura 3D. Para concluir, os monitores explicaram e discutiram com os alunos o conceito de acurácia tátil e o homúnculo para compreensão da variação da sensibilidade ao longo do corpo. 


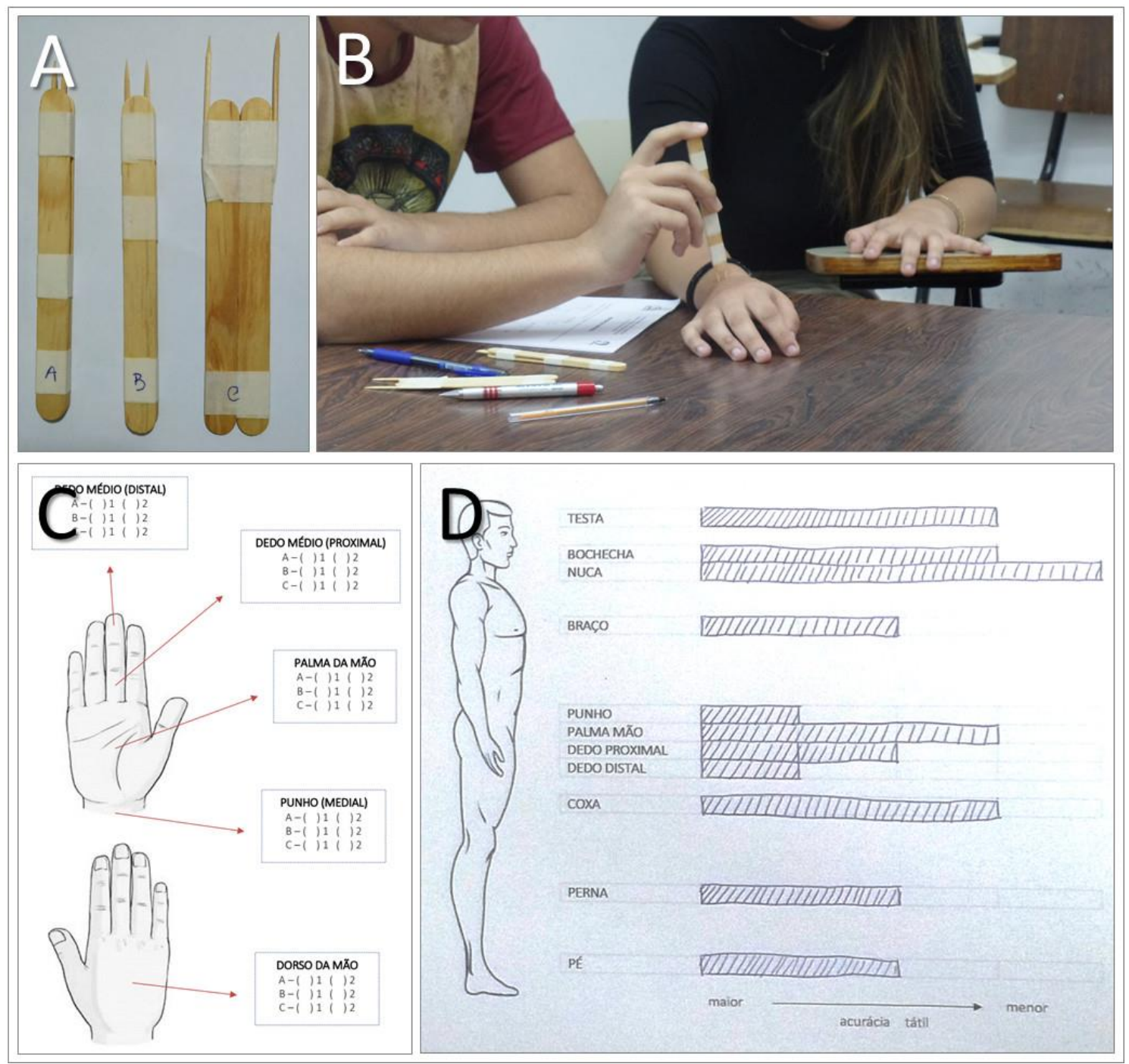

Figura 3 - Tato e acurácia tátil. A, instrumentos criados para a realização do teste, onde os palitos possuem distancias diferentes entre eles. B, aplicação do instrumento sobre o dorso da mão de uma aluna vendada. C, roteiro para anotar a percepção tátil. D, mapa de acurácia tátil do corpo confeccionado a partir da experiencia. Fonte: autores.

Feedback dos alunos sobre o curso

Ao final do curso, os alunos preencheram um formulário impresso que continha os seguintes questionamentos: (1) como eles tomaram conhecimento do curso; (2) opinião sobre a estruturação do curso, com respostas classificadas como "muito bom", "regular" ou "ruim"; (3) pretensão em prestar o vestibular ou ENEM; (4) influência do curso sobre a escolha da carreira profissional; (5) interesse em ingressar em um curso de graduação oferecido pelo ISNF da UFF e; (6) sugestões e críticas. Ainda, foi proposta uma reflexão sobre a experiência deles no curso, através de fragmentos de sentenças que deveriam ser completadas pelo mentimeter: "Eu pensava que..."; "Surpreendeu-me descobrir que...”, "Neurociências é...”. Os 
alunos foram informados e consentiram o uso das informações fornecidas para fins de divulgação científica do projeto.

\section{Resultados e Discussão}

Perfil dos alunos e motivações iniciais

Entre os cursos disponibilizados $(n=8), 20$ alunos escolheram o curso de férias em Neurociências Descomplicada como 1 a opção, 39 alunos como 2a opção e 44 como $3^{\text {a }}$ opção. Entre os 32 alunos selecionados para o curso Neurociências Descomplicada, 58\% residiam no município de Nova Friburgo e $42 \%$ em outros municípios da região serrana do estado do RJ. A maioria estava matriculada no $3^{\circ}(52 \%)$ e $2^{\circ}$ anos $(45 \%)$ do ensino médio e apenas $3 \%$ cursava o pré-vestibular. Entre os selecionados, apenas 20 frequentaram o curso.

Na justificativa para a escolha do curso, alguns alunos apontaram que a experiência permitiria o contato com a profissão que pretendiam seguir, em geral a medicina (neurologia e neurocirurgia), a psicologia e a pedagogia. Alguns alunos apontaram que participar do curso poderia ajudá-los na escolha da carreira profissional. Ainda, alguns justificaram sua escolha por conta do grande fascínio que possuem pelo cérebro e o seu funcionamento. Segundo Paggiaro e Calais (2009), é importante prover aos estudantes oportunidades que ampliem a sua visão sobre a escolha profissional e que forneçam estratégias antiestresse para enfrentar o desafio do vestibular. No curso, os alunos demonstraram uma ideia muito vaga sobre o que é a neurociência, sendo esta reflexão estimulada para que pudessem optar mais acertadamente pela carreira ao realizar o vestibular.

\section{Engajamento durante o curso}

No planejamento e execução das atividades, buscou-se fazê-los de forma que os alunos se mantivessem engajados e participativos nas atividades propostas. Schaufeli et al. (2002) definem o engajamento como um estado afetivo-cognitivo persistente, compreendido como um estado mental positivo, caracterizado por três fatores: vigor, dedicação e absorção. De forma sucinta, o vigor se reflete no desejo em se esforçar na atividade que está sendo executada, a dedicação pelo entusiasmo e interesse na atividade e a absorção refere-se ao envolvimento e imersão na atividade, que gera a sensação do "tempo passar voando" (Schaufeli et al., 2002). Em um primeiro momento, os alunos se mostraram tímidos e 
silenciosos, provavelmente por não conhecerem os demais alunos, a nossa equipe e por estarem em um ambiente novo. Com o andamento das atividades e discussões, eles passaram a interagir com os demais colegas, assim como com os monitores e a docente.

Uma estratégia planejada para "quebrar o gelo" e promover o engajamento foi o uso do mentimeter, uma plataforma que permite à plateia interagir com os slides projetados pelo professor através do seu dispositivo móvel (celulares e tablets). Além do layout atrativo, a interação ocorre de forma anônima, o que evita a exposição do aluno perante a turma ao responder uma questão. As respostas obtidas ficam projetadas na tela e o professor e a turma conseguem visualizar o número de pessoas que interagiram com o slide, mas sem acesso a quem respondeu.

No Brasil, há uma escassa literatura publicada sobre o uso do mentimeter na educação e, no contexto extensionista, foi encontrado apenas um relato de Andrade et al. (2020). No contexto da educação, Pegini (2018) e Vallely e Gibson (2018) também apontaram o anonimato das respostas e o engajamento dos estudantes como vantagens no uso deste aplicativo. Devido ao anonimato, Vallely e Gibson (2018) apontam três estratégias multidisciplinares que podem ser desenvolvidas para engajar: a sondagem de opiniões, a promoção de discussões a partir das respostas obtidas e a expressão de preocupações e questões pelos alunos.

O mentimeter permite o download das respostas em formato .xls, assim como das interações realizadas com os slides em formato de imagem (.jpg) ou documento de texto (.pdf). A Figura 4 ilustra as diferentes formas de interação que foram utilizadas, onde pode-se observar duas perguntas de múltipla escolha, uma pergunta em escala de 0-10, duas perguntas com respostas abertas e uma nuvem de palavras. As perguntas na Figura 4A foram usadas para discutir o tema emoções, enquanto as perguntas da Figura 4B foram utilizadas no fechamento do curso. 


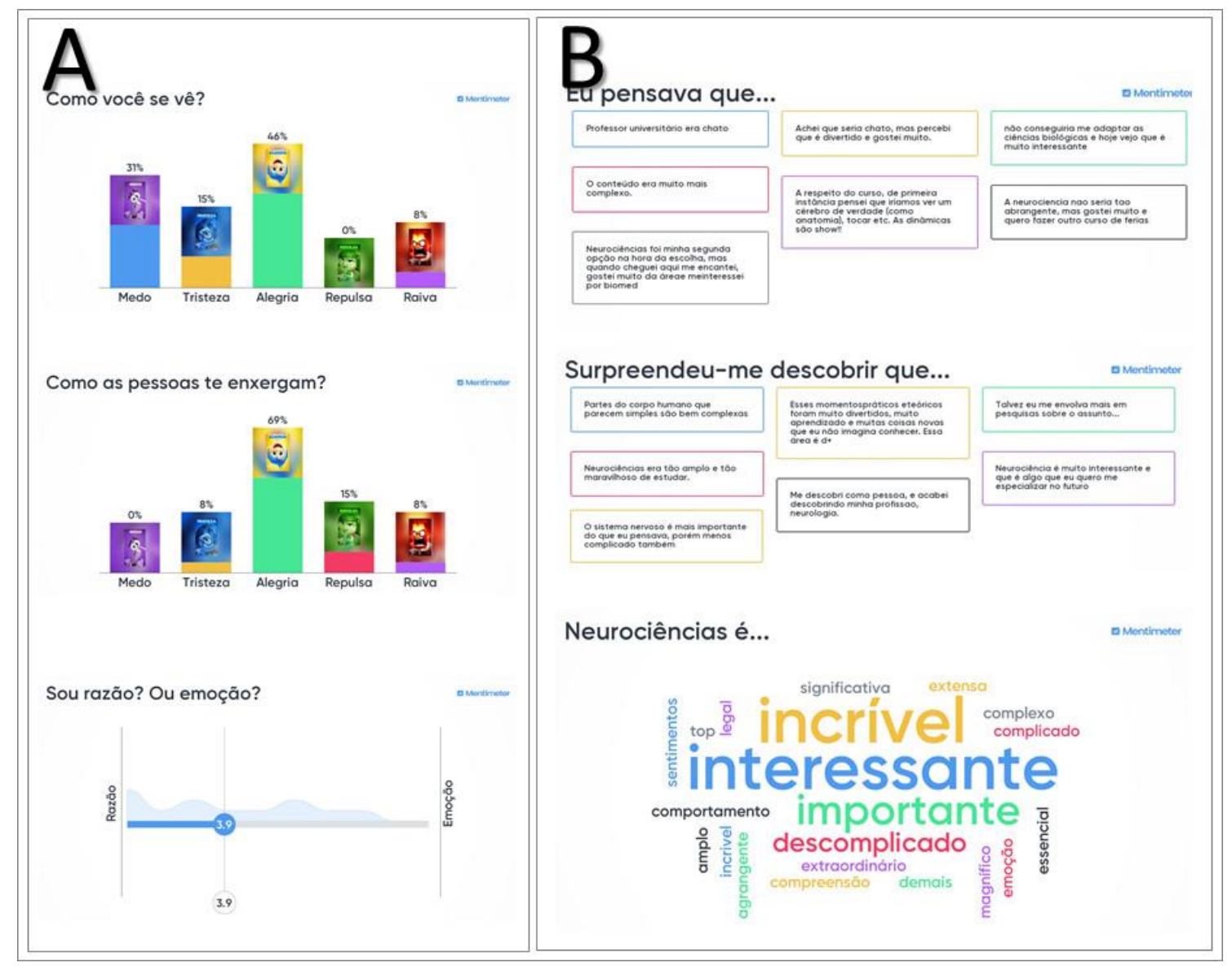

Figura 4 - Engajamento e interação de forma anônima. A, uso do Mentimeter para discutir o tema emoções. B, ao final do curso, o Mentimeter foi utilizado para obter um feedback dos alunos. Fonte: autores.

Trazer o conteúdo para próximo da realidade dos alunos foi uma segunda estratégia utilizada para engajar os alunos e tornar a aprendizagem relevante e significativa. Evitou-se práticas de invasão cultural, onde leva-se através do conteúdo uma visão de mundo daqueles que os levam, de forma a sobrepô-lo àqueles que passivamente o recebem, transformando o indivíduo em "coisa" e o negando como um ser de transformação do mundo (Freire, 1983). As práticas também foram pensadas a partir da Teoria da Aprendizagem Significativa de David Paul Ausubel, onde aquilo que o indivíduo já sabe é o fator isolado que mais influencia a sua aprendizagem. O sujeito deve ter uma predisposição a aprender e os conceitos já existentes servem para ancorar o novo conceito a ser aprendido (Distler, 2015).

O trabalho em pequenos grupos foi uma terceira estratégia utilizada. Cohen e Lotan (2017) define o trabalho em grupo como "alunos trabalhando juntos em grupos pequenos de modo que todos possam participar de uma atividade com tarefas claramente atribuídas". Em um grupo, as atividades seriam desempenhadas sem supervisão direta e imediata do professor 
(Cohen \& Lotan, 2017). Costa (2014) diz que esta estratégia permite a partilha e escuta de opiniões, assim como a colaboração para resolução de problemas complexos. Por fim, o grupo auxilia a construção da dimensão social do aluno, quando eles estão em circunstâncias em que não se conhecem (Costa, 2014), como foi o caso deste curso de férias.

As atividades propostas geraram materiais como, por exemplo, o "chapéu de cérebro" e os roteiros preenchidos, os quais foram levaram espontaneamente ao final do curso pelos alunos. Os roteiros foram disponibilizados em cópia única para o grupo (e não impressos individualmente por aluno) e isso fez com que eles solicitassem esse material, assim como as fotos e vídeos registradas pela equipe, os quais foram compartilhados através da nuvem Google Drive (google.com/drive/). Essas atitudes ratificam o interesse e engajamento dos alunos durante o curso de férias.

Por fim, buscou-se na literatura outras experiencias metodológicas para divulgar a ciência a escolares. Para abordar o tema imunologia, Silva et al. (2018) utilizaram na escola vídeos, palestras, rodas de conversas, jogos, teatralização, panfletos, folders e exposição de lâminas ao microscópio. Para discutir a educação sexual e reprodutiva, Bertollo et al. (2018) realizaram na escola oficinas que consistiam em debates e dinâmicas em grupos, apresentação de slides, imagens e vídeos, assim como gincana e a produção de cartazes. Apesar de conhecer-se a existência de cursos de férias oferecidos por outras universidades, não foi encontrado relatos publicados sobre essas experiencias.

\section{Feedback dos alunos sobre o curso de férias}

Os 20 alunos que preencheram o formulário de feedback responderam que pretendem fazer a prova do ENEM ou vestibular (Figura 5A). Quando questionados se participar do curso de férias ajudou na escolha da carreira profissional futura, 75\% responderam que sim, $5 \%$ que não e para $20 \%$ foi indiferente (Figura 5B). Em conversas ao longo do curso, alguns alunos esboçaram já saber a carreira que irão seguir (p. ex., medicina ou psicologia) e talvez por isso, para alguns alunos, a participação no curso tenha sido indiferente na escolha da carreira.

O vestibular é o momento que marca a saída da escola e o ingresso no ensino superior, onde o jovem deve escolher uma carreira profissional a ser seguida em sua vida adulta. Segundo Levenfus e Nunes (2002), é comum os jovens terem total desconhecimento sobre a profissão de interesse, muitas vezes com visões distorcidas e errôneas. Ainda, há muitos 
cursos para escolha e, apesar de alguns já saberem o que gostariam de cursar, outros possuem três ou quatro opções de escolha (Paggiaro \& Calais, 2009).

Ainda, esta pode ser uma fase da vida turbulenta e cheia de inseguranças, devido a diversos fatores como, por exemplo, a pressão e expectativas de amigos, familiares, professores e da sociedade (Dias et al., 2008). Já foi relatado que as expectativas criadas em relação a esse momento podem gerar transtornos como ansiedade, estresse e até depressão (Dias et al., 2008; Paggiaro \& Calais, 2009). A escolha profissional interfere no bem estar dos jovens e o auxílio nesta decisão promove melhora do desempenho acadêmico, motivação e bem estar, contribuindo para a sua qualidade de vida (Paggiaro \& Calais, 2009). Neste sentido, a oferta de cursos de férias para alunos do ensino médio e curso pré-vestibular pelas universidades é uma ferramenta importante para auxiliar a escolha da carreira futura e talvez promover a redução do estresse e ansiedade inerentes a esse momento.

Um entre os diversos objetivos do curso de férias é divulgar a presença da UFF no interior do estado do RJ para que os seus cursos de graduação - biomedicina, fonoaudiologia e odontologia - se tornem uma opção de escolha entre os jovens da região. Isto porque a busca natural dos jovens é pelos cursos oferecidos nos grandes centros urbanos, sendo os mais próximos as cidades de Niterói e Rio de Janeiro. Contudo, o custo de vida nestes centros é alto e não são todas as famílias que dispõe de recursos para custear a vida de seus jovens em um outro município durante quatro ou cinco anos de formação. Diante disso, o formulário questiona o interesse do aluno em ingressar em um curso de graduação da UFF de Nova Friburgo antes e após ter participado do curso de férias (Figura 5C-D). Apenas $40 \%$ apontou interesse prévio e, após o curso, 3 entre 12 alunos que não apresentavam interesse inicial passaram a tê-lo. Isto mostra que nosso objetivo de divulgar o campus e nossos cursos de graduação está sendo alcançado. Entendemos que não conseguiremos despertar o interesse de todos os jovens pelos nossos cursos. Considerando ainda o público-alvo recebido neste ano, entendemos também que a maioria gostaria de cursar medicina e psicologia, contudo estes não são cursos oferecidos em nosso campus. 


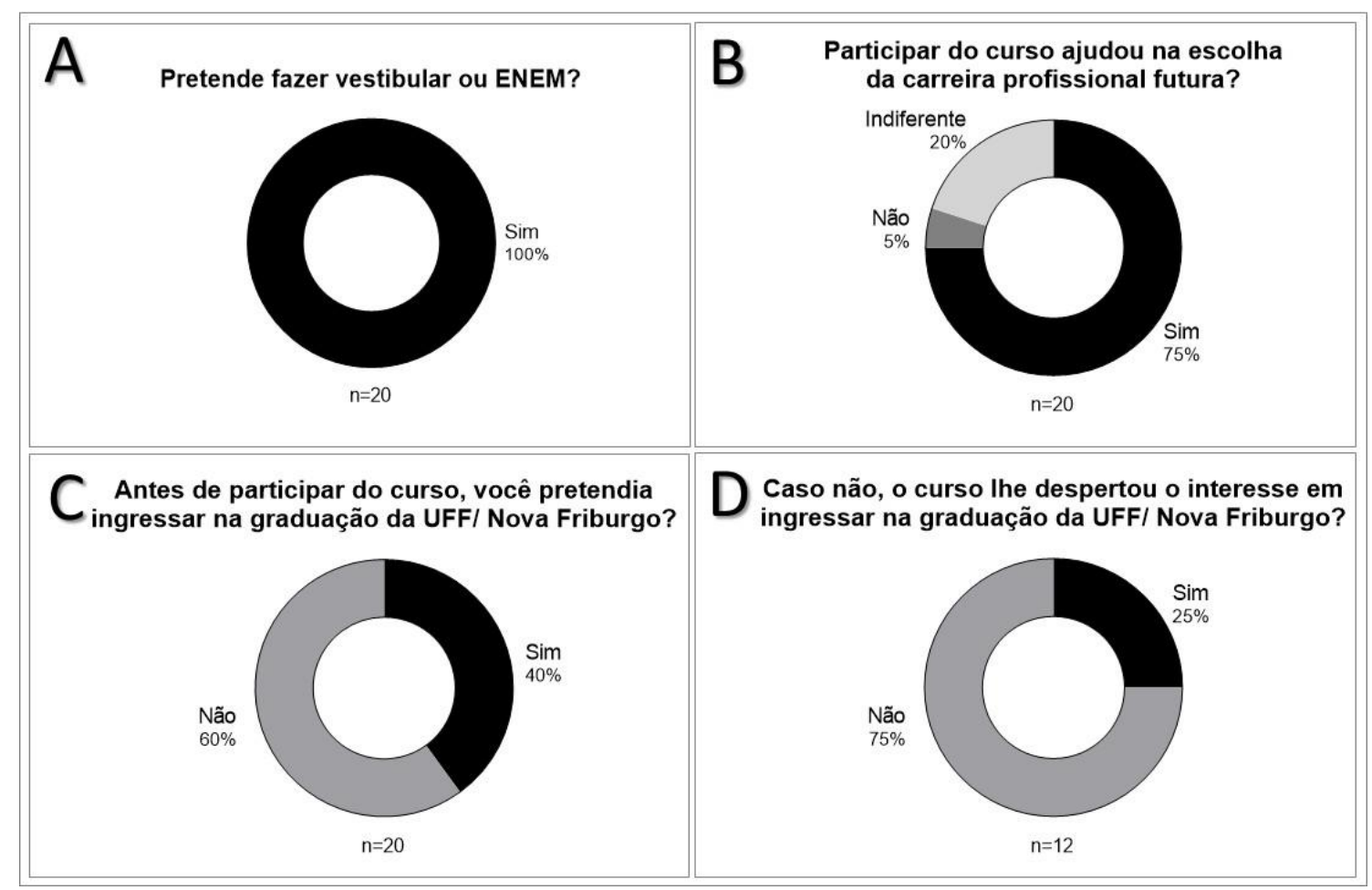

Figura 5 - Avaliação do curso pelos alunos. As respostas foram obtidas através de um formulário impresso. Fonte: autores.

Todos os alunos (100\%) avaliaram como "muito bom” a recepção deles pela docente, o apoio dos monitores e os conteúdos abordados. Sete alunos (35\%) avaliaram a duração do curso como regular e, no campo aberto de críticas e sugestões, eles apontaram que o curso poderia ser oferecido em um número maior de dias ou mais de uma vez ao ano. Os cursos são oferecidos sempre uma vez ao ano, durante o período de recesso escolar da universidade e escolas do município. A duração do curso é uma crítica constante ao longo dos anos, mesmo quando possui uma semana de duração. Por um lado, os docentes precisam equilibrar as atividades de ensino, pesquisa e extensão e dispor de mais tempo para oferta de cursos nem sempre é possível. Por outro lado, a crítica dos alunos aponta que há interesse pelo projeto, o que motiva a sua continuação.

\section{Reflexões sobre a formação acadêmica dos extensionistas}

Os monitores do curso de férias são alunos cursando a graduação em biomedicina e fonoaudiologia, cursos estes que possuem a disciplina de Neurociências em seu currículo. De acordo com as diretrizes curriculares nacionais destes dois cursos, é necessário que os alunos participem de atividades onde possam aplicar os conhecimentos adquiridos durante a 
graduação, sendo a extensão uma oportunidade para tal. A resolução n ${ }^{\circ} 7$ de 18 dez 2018, que estabelece as diretrizes para a extensão na educação superior brasileira, diz que deve haver uma interação dialógica entre a comunidade acadêmica e a sociedade e que a prática da extensão no ensino superior deve contribuir para a formação integral dos estudantes, estimulando sua formação como cidadãos críticos e responsáveis. Dessa forma, a participação neste projeto é importante a formação acadêmica, conforme evidenciado nos recortes de falas dos monitores:

“[...] me proporcionou além de aprofundar conhecimentos que aprendi ao longo da faculdade, adquirir também novos conhecimentos, bem como aprender novas metodologias inovadoras de ensinoaprendizagem [...]consegui perceber o quanto é possível tornar o conhecimento científico muito mais didático e estimulante [...]."

"[...] a equipe recebeu um bom retorno dos alunos quanto as atividades, com palavras de empolgação, agradecimento, e o despertar do interesse pela neurociências; o que traz a alegria de saber que os objetivos foram cumpridos, e o reconhecimento de que a escolha dos temas, atividades e metodologia didática foi assertiva [...]”,

Silva et al. (2018) aponta que a divulgação de ciência aos jovens no ambiente escolar, promoveu o crescimento pessoal dos alunos de graduação em enfermagem envolvidos, os quais se tornaram capacitados a atuar na promoção da saúde comunitária, através da educação em saúde, habilidades estas que serão essenciais ao desempenho futuro de sua profissão. Nas oficinas realizadas por estudantes de medicina no ambiente escolar, Bertollo et al. (2018) relataram como positivo estar fora da sala de aula e abrir as portas da universidade. Ao prepararem e conduzirem as oficinas, os graduandos apresentaram melhora global na aquisição de conhecimento teórico sobre os temas abordados, assim como melhora das capacidades comunicativas e de ensino.

\section{Considerações finais}

Ao planejar ações de divulgação da ciência, deve-se pensar em atividades lúdicas, interativas e dialógicas, que abordem questões do cotidiano dos alunos. Nota-se que atividades que expõe os jovens ao ambiente universitário ainda no ensino médio são de 
extrema importância. Além do aprendizado de assuntos não abordados nas escolas, os jovens conhecem os professores e alunos da universidade. Esta experiencia os aproxima à vida acadêmica e profissão pretendida, assim como os auxilia na decisão da carreira profissional.

Acreditamos também que a divulgação científica exerce um importante papel na busca pela valorização da ciência. Nesse caminho, aproximar a comunidade da academia constitui uma ferramenta de combate a ideias conspiratórias observadas na sociedade contemporânea que ameaçam o desenvolvimento científico-tecnológico, a exemplo do terraplanismo e antivacinação. Dessa forma, educar a população sobre o método científico e estimular o pensamento crítico são caminhos para driblar as fake news e pseudociências. Além disso, pode trazer a sociedade para um debate em defesa dos investimentos em educação, conforme contextualizado previamente.

O curso Neurociências Descomplicada foi oferecido novamente em 2019, neste mesmo formato, porém sob o nome Desvendando o Cérebro, para aumentar o número de inscritos, o que de fato ocorreu. O feedback recebido na $2^{\mathrm{a}}$ edição em 2019 foi semelhante aos relatos de 2018, sendo assim optou-se por manter o mesmo formato metodológico nas próximas edições do curso.

\section{Agradecimentos}

Aos alunos bolsistas de desenvolvimento acadêmico, pela organização das inscrições, seleção dos alunos e confecção de certificados.

\section{Contribuição de cada autor}

Os autores A.M-S, M.L.M.L., M.P.D., P.B.C., T.B.F.S. e C.F-S. participaram da concepção e o delineamento do estudo, realizaram as atividades descritas e fizeram a aquisição, análise e interpretação dos dados do trabalho. A.M-S, M.L.M.L. e M.P.D. redigiram o manuscrito e C.F-S fez a revisão crítica do conteúdo intelectual. Todos os autores aprovaram a versão final do manuscrito. 


\section{REFERÊNCIAS}

Andrade, D. C. M., Brum, A. K. R., Neves, R. P. S., Calvo, D. G. M., \& Silva, D. M. L. (2020). Uso de ferramentas digitais interativas em encontro para o ensino da segurança do paciente. Brazilian Journal of Health Review, 3(2), 1531-1541. Disponível em: http://www.brjd.com.br/index.php/BJHR/article/view/7461.

Bertollo, L. P. G., Martins, R. R., \& Ayres, J. R. C. M. (2018). Educação sexual e reprodutiva para adolescentes como educação entre pares: avaliação de uma experiência de extensão universitária. Revista Brasileira de Extensão Universitária, 9(2), 83-91. Disponível em: https://periodicos.uffs.edu.br/index.php/RBEU/article/view/7918.

Cerri, B. R., Hoffmann, J. S., Rocha, L. C., Amorim, L. A., Rabelo, T. M., Moro, Y. M., Anaruma, C. A., \& Ciena, A. P. (2015). Projeto de extensão: anatomia humana para os ensinos fundamental e médio. In $8^{\circ}$ Congresso de extensão universitária da UNESP. (pp. 1-6). Disponível em: http://hdl.handle.net/11449/142695.

Cohen, E. G., \& Lotan, R. A. (2017). Trabalho em grupo como estratégia pedagógica. In E. G. Cohen, R. A. Lotan (Eds), Planejando o trabalho em grupo: estratégias para salas de aula heterogêneas. (pp. 1-6). Porto Alegre: Penso.

Costa, M. J. (2014). Trabalhos em pequenos grupos: dos mitos à realidade. Medicina (Ribeirão Preto), 47(3), 308-13. Disponível em: http://www.revistas.usp.br/rmrp/article/view/86620.

Dias, L. S., Nazareno, E., Zanini, D. S., \& Mendonça, H. (2008). Vestibular e Adolescência: perspectivas teóricas e implicações sociopsicológicas. Revista Fragmentos de Cultura, 18(4), 625-636. Disponível http://seer.pucgoias.edu.br/index.php/fragmentos/article/view/712/541.

Distler, R. R. (2015). Contribuições de David Ausubel para a intervenção psicopedagógica. Revista Psicopedagogia, 32(98), 191-199. Disponível em: http://pepsic.bvsalud.org/scielo.php?script=sci_arttext\&pid=S0103-84862015000200009.

Freire, P. (1983). Extensão ou comunicação? (7. ed.). Rio de Janeiro: Paz e Terra.

Ivanissevich, A. (2009). A missão de divulgar ciência no Brasil. Ciência e Cultura, 61(1), 4-5. Disponível em: http://cienciaecultura.bvs.br/scielo.php?script=sci_arttext\&pid=S0009$\underline{67252009000100002 .}$.

Learn.Genetics. Mouse Party. Disponível em: https://learn.genetics.utah.edu/content/addiction/mouse/?src=asp-cu\&typ=dl\&cid=3408.

Levenfus, R. S., \& Nunes, M. L. T. (2002). Principais temas abordados por jovens centrados na escolha profissional. In R. S. Levenfus, D. H. P. Soares (orgs.), Orientação vocacional ocupacional: Novos achados teóricos, técnicos e instrumentais para a clínica, a escola e a empresa. (pp. 61-78). Porto Alegre, Artmed.

Mchenry, E. J. (2000). Brain hat. Disponível em: http://ellenjmchenry.com/brain-hemisphere-hat/.

Paggiaro, P. B. S., \& Calais, S. L. (2009). Stress e escolha profissional: um difícil problema para alunos de curso pré-vestibular. Contextos Clínicos, 2(2), 97-105. Disponível em: http://pepsic.bvsalud.org/scielo.php?script=sci_arttext\&pid=S1983-34822009000200004.

Schaufeli, W. B., Salanova, M., González-Romá, V, \& Bakker, A. B. (2002). The measurement of engagement and Burnout: A two sample confirmatory factor analytic approach. Journal of 
Happiness Studies, 3, 71-92. Disponível em: https://link.springer.com/article/10.1023\%2FA\%3A1015630930326.

Silva, A. M., Zanesco, C., Cazarotto, A. R., Borsoi, F. T., Dervanoski, C., Marolli, C., Zanella, K. A., Silva, D. T. R., Bagatini, M. D. (2016a). O ensino de ciências biológicas - uma experiência teórico-prática com alunos do ensino médio de escolas públicas. Revista Brasileira de Extensão Universitária, 7(2), 99-104. Disponível em: https://periodicos.uffs.edu.br/index.php/RBEU/article/view/3086.

Silva, R. P. M., Lucena, B. M., Carneiro, F. D., Emerich, A. S., Almeida, D. P. R., Salvador, H. C. M., Rodrigues, L. G., Alves, M. M., Silva, M. I. L. S., Gregorio, B. M., Nascimento, F. A. M., \& Fernandes-Santos, C. (2016b). Programa consCIÊNCIA na CIÊNCIA: Divulgação Científica no Ensino Médio através de um Curso de Férias em Nutrição. Revista Brasileira de Extensão Universitária, $\quad 7(2), \quad 145-153 . \quad$ Disponível em: https://periodicos.uffs.edu.br/index.php/RBEU/article/view/3109.

Silva, B. N., Souza, T. G., Vieira, J. K. S., Silva, M. Z. C., Farias, V. E., Silva, L. H., Rodrigues, J. A. S., Araújo, L. L., \& Assis, L. M. (2018). Imunologia nas escolas: experiências de um projeto de extensão. Revista Brasileira de Extensão Universitária, 9(2), 93-98. Disponível em: https://periodicos.uffs.edu.br/index.php/RBEU/article/view/7669.

Takase, E. (2003). Contribuições Recentes da Neurociência à Psicologia. Revista de Ciências Humanas, 34, 441-458. Disponível em: https://periodicos.ufsc.br/index.php/revistacfh/article/view/25386.

Vallely, K. S. A., \& Gibson, P. (2018). Engaging students on their devices with Mentimeter. Compass: Journal of Learning and Teaching, 11(2). Disponível em: https://journals.gre.ac.uk/index.php/compass/article/view/843. 